\title{
Вмј Global Health Flashing red lights: the global implications of COVID-19 vaccination passports
}

\author{
Kristin Voigt, ${ }^{1}$ Evrard Nahimana, ${ }^{2}$ Anat Rosenthal ${ }^{3}$
}

To cite: Voigt $\mathrm{K}$, Nahimana $\mathrm{E}$, Rosenthal A. Flashing red lights: the global implications of COVID-19 vaccination passports. BMJ Global Health 2021;6:e006209. doi:10.1136/ bmjgh-2021-006209

Received 5 May 2021 Accepted 8 May 2021
Check for updates

C) Author(s) (or their employer(s)) 2021. Re-use permitted under CC BY-NC. No commercial re-use. See rights and permissions. Published by BMJ.

${ }^{1}$ Institute for Health and Social Policy \& Department of Philosophy, McGill University, Montreal, Québec, Canada ${ }^{2}$ Partners In Health, Kigali, Rwanda

${ }^{3}$ The Department of Health Policy and Management, Schoo of Public Health, Faculty of Health Sciences, Ben-Gurion University of the Negev, Beer Sheva, Israel

Correspondence to

Dr Kristin Voigt;

kristin.voigt@mcgill.ca

\section{INTRODUCTION}

As COVID-19 vaccination roll-outs are progressing in wealthy parts of the world, several countries are implementing or investigating COVID-19 vaccination passports that restrict access to restaurants, sports events or universities to those who have been fully vaccinated against COVID-19. While these discussions focus on domestic implementation, we must assume that, once introduced, vaccination passports will be applied to international travel. We argue that the global health community must participate in the debate about such schemes with an eye to equity and highlight their global implications.

We emphasise two concerns. First, vaccination passports attached to international travel before equitable access to vaccines has been established will exacerbate global inequalities by effectively excluding from travel the millions of citizens of poor countries who are suffering from the health impact and the social and economic fallout of the pandemic, with little prospect of gaining access to vaccines any time soon. Such inequalities are rooted in a long history of colonialism and exploitation; global restrictions based on vaccination status will amplify these historic injustices. Second, such schemes will undermine global solidarity, increasing the risk that the pandemic is seen as a local issue rather than a genuinely global problem.

\section{GLOBAL INEQUALITY AND VACCINATION PASSPORTS}

Vaccination passports raise many ethical issues. Arguments for restrictions on people's freedoms, such as lockdowns or quarantines, lose their traction when individuals have been fully vaccinated and therefore-as increasing evidence suggests-no longer pose significant risk of transmitting SARS-CoV-2. Vaccination passports, this argument goes, allow
Summary

COVID-19 vaccination passport schemes tied to international travel threaten to widen global inequalities and to undermine global solidarity.

- Until COVID-19 vaccinations are a global public good, accessible to all countries, the global health community should caution against restrictions on international travel based on vaccination status.

- The interests of citizens of low/middle-income countries must become part of this debate.

- Global health professionals should engage in domestic policy conversations about vaccination passports because they have global implications.

the selective imposition of restrictions only on those who in fact pose a risk to others. Vaccination passports allow the resumption of economic, educational and cultural activities brought to a halt during the pandemic and could incentivise hesitant citizens to get vaccinated.

While such schemes are controversial in many countries, the debate assumes that vaccination passports will apply to international travel. The details, however, remain murky: the idea seems to be that current entry restrictions and quarantine requirements would be lifted for vaccinated travellers. It is much less clear what would happen to those who are unvaccinated. They may remain subject to current requirements, for example, to quarantine, at their own cost, for 14 days. While not formally preventing unvaccinated people from travel, such financial barriers will exclude many low-income travellers. The unvaccinated could also be prevented from travelling internationally altogether. Recent experience has shown how quick countries are to close their borders to noncitizens from regions with high incidence of COVID-19 or indeed to all non-residentssome even blocking return of their own citizens. Airlines are exploring ways to restrict 
travel to vaccinated passengers. We do not know whether negative COVID-19 tests would be accepted as an alternative to vaccination and how accessible these tests will be worldwide.

In wealthy countries, these debates assume that the vaccine is, or soon will be, available to the entire (medically eligible) population. ${ }^{1}$ This assumption, of course, only holds for rich countries. Low/middle-income countries (LMICs) have not been able to compete for the small supply of vaccines produced. Global initiatives to expand access to vaccines in LMICs such as COVAX are failing to meet demand and struggle to find an equitable and effective model of distribution. ${ }^{23}$ Despite early calls for adjustments to intellectual property and patenting regulations that stand in the way of global access to pharmaceuticals, the current situation is depressingly familiar: it may be years until legal frameworks and trade agreements will make vaccine technologies widely available and allow poor countries to gain access to COVID-19 vaccinations. ${ }^{4}$

When the impact of COVID-19 on poor countries enters the conversation, what is emphasised is often that the age profiles of poorer populations make them less susceptible to the virus, and that their experience with epidemics such as Ebola strengthens their response to COVID-19. What has received much less attention is the massive toll of the pandemic on poor countries. This includes, of course, COVID-19 morbidity and mortality but also social, political and economic effects, such as food insecurity and poverty. ${ }^{5}$ Disruption of crucial healthcare services, such as malaria control, child vaccination programmes or women's health, is expected to cause large numbers of deaths. ${ }^{6-9}$ In some countries, the pandemic has also led to an increase in child marriages. ${ }^{10}$ Many of these effects are expected to extend beyond the current pandemic.

As poor countries are struggling with the fallout of the pandemic, an equitable global distribution of vaccinations is not expected to materialise in the near future. In this context, schemes that tie international travel to vaccination add insult to injury: not only can citizens of poor countries not get vaccinated and are excluded from the technologies enabling a release from the risks of the pandemic, they now also face further restrictions on their freedom of movement as a result of vaccine passports and vaccine-based travel restrictions. Rather than supporting them in their efforts to combat COVID-19, vaccination passports exclude and isolate poor countries, no matter how well they are controlling the spread of COVID-19.

While some countries may see passport schemes as a way to safely revitalise tourism, most low-income countries are not tourist destinations and have little to gain from passport schemes. Vaccine passports will exacerbate existing inequalities between rich and poor countries but also within poor countries, as richer citizens in urban areas gain access to vaccines first, well before poor populations in remote areas. Any talk of vaccine passports and international travel must be preceded by equitable access to vaccines.
VACCINATION PASSPORTS AND GLOBAL SOLIDARITY

In stark contrast with previous global health crises, wealthy countries have not been isolated from the effects of the pandemic. Even the world's wealthiest countries have faced situations that had previously been associated with the 'developing world': overwhelmed hospitals, triage of medical supplies and technologies, and hospital morgues filled beyond capacity.

We might have hoped that this shared vulnerability to a common threat would strengthen global solidarity and a commitment to treat the pandemic as the global problem that it is. ${ }^{11}$ The past few months, however, have shown that this picture is overoptimistic, to say the least. As the global economic shutdown was felt acutely in poor countries where industry and production came to a halt, the situation of LMICs and how it was worsened by measures adopted in the Global North received little attention. ${ }^{5}$ While commentators revelled in the 'same storm' metaphor, it was painfully clear that the world was experiencing this storm in very different 'boats'. While initiatives such as COVAX were initiated to mitigate the access gap, recent months have seen rich countries walking back on their promises and accumulating vaccines, ${ }^{2}$ leaving poor countries, despite their best efforts, struggling to vaccinate their first responders, let alone high-risk groups and the general population. While it took a relatively short period (42 days) for the first low-income country to receive COVID-19 vaccines through COVAX, for the majority of LMICs universal access may not happen for another 3 or 4 years. At the same time, rich countries are beginning to order second, third and fourth rounds of vaccinations for their populations.

Vaccination passports threaten to further undermine global solidarity by creating two classes of people: those who can go back to prepandemic (semi) 'normal', free to travel for business and pleasure with little restriction, and those whose freedoms remain curtailed until vaccines reach poor countries. This reality is familiar from other global health emergencies, most notably, the HIV epidemic and the decade's delay in turning the disease from acute to chronic when treatment was unattainable to the most vulnerable. The 'HIV treatment for all' statements as well as lengthy legal struggles made history in opening access to much-needed drugs in poor countries. The global health community played a major role in paving the way for governmental and international partnerships and initiatives.

While history has seen stories of success in coping with pandemics through solidarity, WHO and local governments are failing in creating institutional structures that could facilitate global cooperation. As rich countries assume new versions of normality, we must encourage new and old forms of solidarity. Much like the AIDS crisis, the SARS-CoV-2 crisis will not be resolved without a global solution. Without providing vaccines as a global public good, the world will not emerge safely from the pandemic. 


\section{CONCLUSION}

Global health professionals often see domestic policy conversations as outside their areas of expertise. But vaccination passports are not an exclusively domestic issue. Now is the time for global health professionals to highlight the global implications of such schemes and to ensure that the interests of LMIC citizens become part of this debate. Tying international travel to vaccination, at a time when most of the world's population is prevented from accessing vaccines, without offering alternative measures, such as free and accessible COVID-19 tests for travellers from LMICs, will widen the gap between the haves and the have-nots, and should be a flashing red light in the face of the global health community.

Contributors AR and KV conceptualised the commentary and wrote the first and subsequent drafts. EN provided comments during subsequent drafts. All authors approved the final version.

Funding This work was supported by the Social Sciences and Humanities Research Council of Canada (SSHRC), grant no. 435-2019-0566.

Competing interests None declared.

Patient consent for publication Not required.

Provenance and peer review Not commissioned; internally peer reviewed.

Open access This is an open access article distributed in accordance with the Creative Commons Attribution Non Commercial (CC BY-NC 4.0) license, which permits others to distribute, remix, adapt, build upon this work non-commercially, and license their derivative works on different terms, provided the original work is properly cited, appropriate credit is given, any changes made indicated, and the use is non-commercial. See: http://creativecommons.org/licenses/by-nc/4.0/.

\section{REFERENCES}

1 Barak-Corren N, Enoch D, Heyd D. Personal decisions, public consequences: on distinguishing between the vaccinated and the Non-Vaccinated in coronavirus management, 2021. Available: https://papers.ssrn.com/sol3/papers.cfm?abstract_id=3793188

2 The Lancet. Access to COVID-19 vaccines: looking beyond COVAX. Lancet 2021;397:941.

3 Herzog LM, Norheim OF, Emanuel EJ, et al. Covax must go beyond proportional allocation of covid vaccines to ensure fair and equitable access. BMJ 2021;372:m4853.

4 von Bogdandy A, Villareal P. The role of international law in vaccinating against COVID-19: appraising the COVAX initiative. MPIL research paper series, no 2020-46. Heidelberg: Max Planck Institute for Comparative Public Law and International Law, 2020.

5 Laborde D, Martin W, Swinnen J, et al. COVID-19 risks to global food security. Science 2020;369:500-2.

6 Roberton T, Carter ED, Chou VB, et al. Early estimates of the indirect effects of the COVID-19 pandemic on maternal and child mortality in low-income and middle-income countries: a modelling study. Lancet Glob Health 2020;8:e901-8.

7 WHO. More than 117 million children at risk of missing out on measles vaccines, as COVID-19 surges. Statement by the Measles \& Rubella Initiative: American Red Cross, U.S. CDC, UNICEF, UN Foundation and WHO, 2020. Available: https://www.who.int/ immunization/diseases/measles/statement_missing_measles_ vaccines_covid-19/en/ [Accessed 24 Apr 2021].

8 Weiss DJ, Bertozzi-Villa A, Rumisha SF, et al. Indirect effects of the COVID-19 pandemic on malaria intervention coverage, morbidity, and mortality in Africa: a geospatial modelling analysis. Lancet Infect Dis 2021;21:59-69.

9 Hogan $A B$, Jewell BL, Sherrard-Smith E, et al. Potential impact of the COVID-19 pandemic on HIV, tuberculosis, and malaria in lowincome and middle-income countries: a modelling study. Lancet Glob Health 2020;8:e1132-41.

10 UNICEF. COVID-19: a threat to progress against child marriage. New York: UNICEF, 2021.

11 West-Oram PGN, Buyx A. Global health solidarity. Public Health Ethics 2017;10:212-24. 